\title{
Studi Pola Arus Bocor Isolator Keramik Selama Waktu Pemakaian 24 Jam
}

\author{
Dini Fauziah ${ }^{1}$, Waluyo ${ }^{2}$, Ismail Muhammad Khaidir ${ }^{3}$ \\ ${ }^{123}$ Jurusan Teknik Elektro, Fakultas Teknik Industri, ITENAS, Bandung \\ Email: dinifauziah@itenas.ac.id
}

\begin{abstract}
ABSTRAK
Isolator merupakan komponen yang penting dijaga keandalannya dalam sistem transmisi dan distribusi tenaga listrik. Isolator rentan mengalami kegagalan akibat lingkungan, karena terpapar langsung kondisi dimana isolator tersebut terpasang. Salah satu jenis isolator yang sering digunakan adalah bahan keramik, dimana memiliki kelebihan diantaranya kekuatan mekanik yang cukup handal. Namun kekurangan isolator jenis ini adalah sifat permukaannya yang hidrofilik, yaitu mudah menyerap air sehingga bila digunakan pada kelembaban tinggi cenderung memicu timbulnya arus bocor. Arus bocor merupakan parameter penting pada isolator karena sering menjadi penyebab kegagalan isolator. Untuk mengetahui seberapa besar pengaruh kondisi lingkungan terhadap arus bocor, dilakukan pengujian terhadap isolator keramik dalam waktu 24 jam. Data arus bocor diambil setiap 3 jam untuk melihat perubahannya berdasarkan perubahan kelembaban, dan suhu lingkungan. Hasilnya didapat bahwa semakin tinggi kelembaban udara, dan semakin rendah suhu lingkungan maka arus bocor semakin tinggi. Hasil penelitian ini dapat dijadikan acuan untuk mengantisipasi kegagalan isolator keramik akibat arus bocor sehingga keandalan sistem tenaga listrik dapat terjaga.
\end{abstract}

Kata kunci: Isolator keramik, Lingkungan, Kelembaban, Suhu.

\begin{abstract}
Isolator is an important component that must be maintained to keep electric power transmission and distribution system reliability. Isolators are susceptible to failure due to the environment, because they are directly exposed to conditions where the insulator installed. Ceramic insulator is one type of isolator that is often used, which has advantages including mechanical strength that is quite reliable. However, the lack of this type of isolator is its hydrophilic surface, which is easy to absorb water so that when used at high humidity tends to trigger a leakage current. Leakage current is an important parameter in an insulator because it can be a cause due to insulator failure. To find out how environmental conditions impact on leakage currents along day, a ceramic isolator is tested within 24 hours. Leakage current data is taken every 3 hours to see the changes based on changes in humidity, and ambient temperature. The result is the higher humidity of the air, and the lower ambient temperature, can make insulator leakage current rise up. The results of this study can be used as a reference to anticipate the failure of ceramic insulators due to leakage currents so that the reliability of the electric power system can be maintained.
\end{abstract}

Keywords: ceramic insulator, environtment, humidity, temperature. 


\section{PENDAHULUAN}

Kebutuhan energi listrik hari demi hari semakin meningkat, perlu dilakukannya suatu perencanaan dalam sistem ketenagalistrikan yang dapat menyediakan energi listrik yang handal. Keandalan suatu sistem tenaga listrik salah satunya ditopang oleh perencanaan sistem transmisi dan distribusi yang baik, dimana salah satu komponen utama dari sistem distribusi dan transmisi adalah isolator.

Salah satu jenis isolator yang sering digunakan adalah jenis isolator keramik dimana memiliki kelebihan pada kekuatan mekaniknya sehingga tidak mudah mengalami kerusakan ketika mengalami degradasi akibat cuaca. Namun kekurangan jenis isolator ini adalah dari sifat hidrofiliknya yang membuat air mudah menyerap di permukaan isolator dan memicu terjadinya arus bocor.

Arus bocor merupakan suatu besaran yang unik, dimana selalu berubah-ubah tergantung kondisi lingkungan pada saat pengukuran dilakukan sehingga monitoring secara terusmenerus penting dilakukan untuk mengetahui kondisi actual dari permukaan isolator. [1]. Kondisi lingkungan yang dimaksud adalah kelembaban dan temperature dimana kedua parameter ini sangat erat korelasinya dengan perubahan arus bocor [2] Sehingga dapat dikatakan bahwa arus bocor merupakan alat diagnosis bagi sebuah isolator yang penting untuk diketahui setiap saat.

Pada beberapa area pemasangan isolator, terdapat polusi tergantung pada kondisi lingkungan isolator tersebut dipasang. Pada beberapa tempat polusi tersebut sangat rendah sehingga tidak berpengaruh secara signifikan. Namun pada area seperti pantai [3], geothermal [4] dan area industri [5] tingkat polusi perlu dipertimbangkan dalam analisis arus bocor isolator karena akan berpengaruh pada flashover isolator tersebut. [6,7]. Arus bocor isolator merupakan alat monitoring yang cukup akurat karena merepresentasikan aktifitas permukaan yang berkaitan dengan kondisi elektrik nya akibat tekanan lingkungan [8]. Semakin tinggi kelembaban di lingkungan sekitar isolator, maka semakin tinggi arus bocor yang dapat terjadi [9].

\subsection{Sampel yang digunakan}

\section{METODOLOGI}

Sampel yang digunakan pada pengujian ini adalah keramik isolator jenis pin dengan tegangan nominal $12 \mathrm{kV}$. Sampel ditunjukkan pada gambar 1 . 


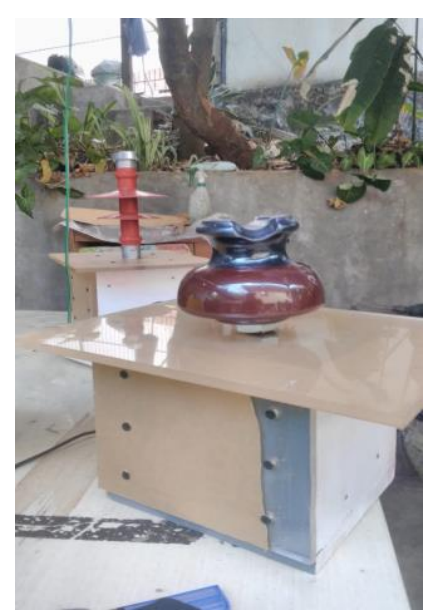

Gambar 1. Sampel isolator keramik yang digunakan

\subsection{Pengambilan Data Arus Bocor}

Pengambilan data arus bocor isolator dilakukan dengan memberikan tegangan nominal secara terus menerus pada kondisi udara luar. Penelitian bertujuan untuk mengetahui kinerja isolator keramik dalam pemakaian 24 jam. Oleh karena itu pengukuran dilakukan setiap 3 jam sebanyak 8 kali. Pada setiap pengukuran arus bocor, dilakukan juga pengukuran parameter lingkungan yaitu kelembaban, suhu dan intensitas cahaya untuk melihat pengaruhnya terhadap arus bocor.

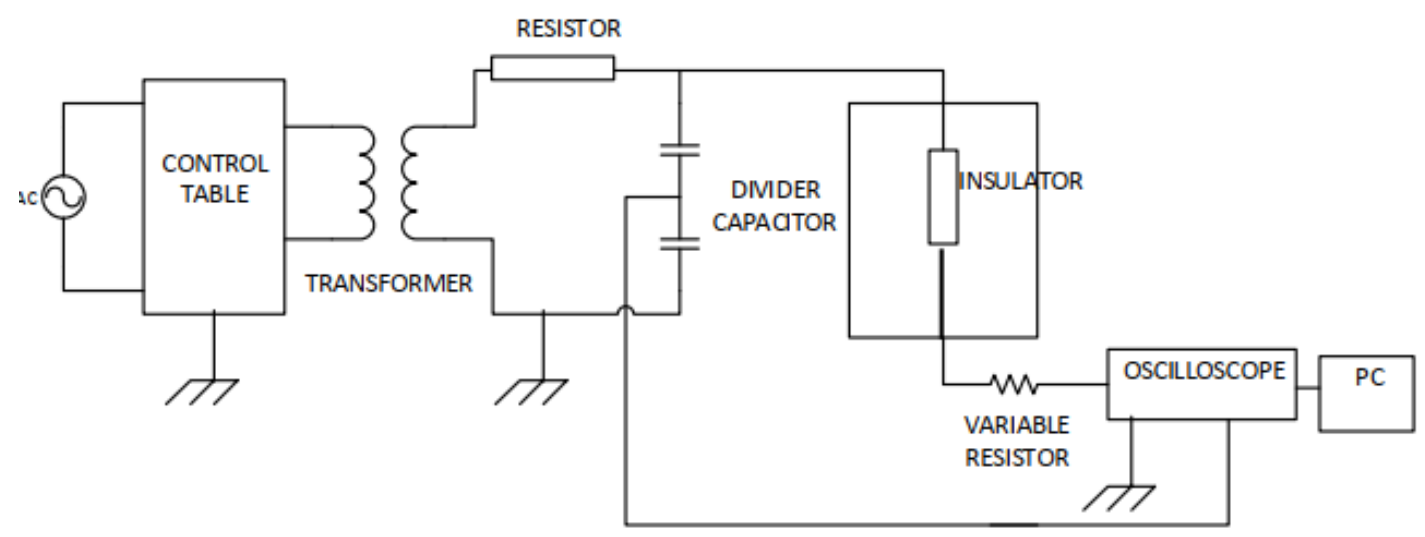

Gambar 2. Rangkaian pengujian arus bocor

Rangkaian pengujian arus bocor ditunjukkan pada gambar 2. Arus bocor yang mengalir di permukaan isolator diukur dengan mengambil data tegangan yang melalui variable resistor seri melalui osiloskop yang selanjutnya diolah melalui komputer. Kemudian untuk mengetahui tegangan yang masuk ke isolator, tegangan sumber juga diukur yaitu melalui divider capacitor yang terpasang sebagai pembagi tegangan sehingga dapat terbaca diosiloskop.

\subsection{Pengukuran Parameter Lingkungan}

Parameter lingkungan yang diukur adalah kelembaban, suhu dan intensitas cahaya. Kelembaban dan suhu diukur menggunakan higrometer yang ditunjukkan pada gambar 3 . Sedangkan intensitas cahaya diukur menggunakan lux meter yang ditunjukkan pada gambar 
4. Pengambilan data parameter lingkungan selalu dilakukan setiap pengambilan data arus bocor untuk mengetahui pengaruhnya.

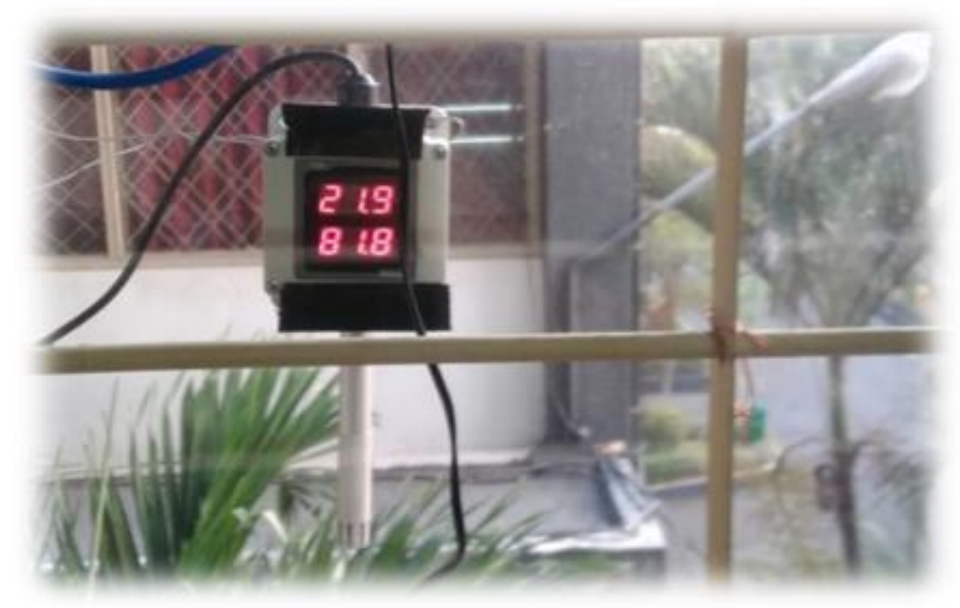

Gambar 3. Pengukuran suhu dan kelembaban

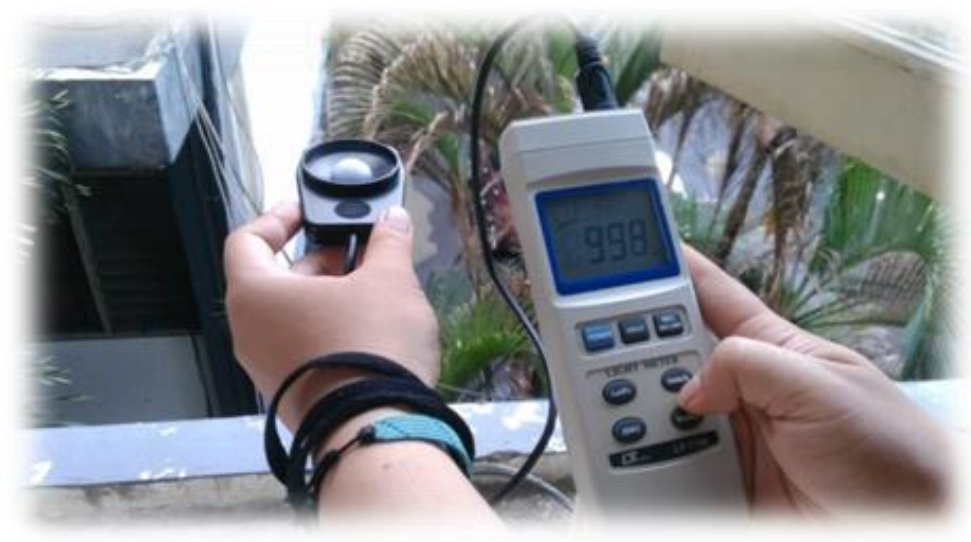

Gambar 4. Pengukuran intensitas cahaya

\section{HASIL DAN PEMBAHASAN}

Tabel 1 menunjukkan parameter yang terukur pada setiap pengukuran arus bocor. Terlihat bahwa pada setiap pengukuran, parameter lingkungan berubah tergantung waktu. Kelembaban tertinggi sebesar $90.80 \%$ terjadi pada pukul 6.00 sedangkan terendah sebesar 37.90 pada pukul 12.00. Intensitas cahaya tertinggi yaitu 88100 pada pukul 12.00 sedangkan terendah sebesar 0.66 pada pukul 21.00. Suhu tertinggi sebesar 31.4 yaitu pada pukul 12.00 dan terendah sebesar 22.2 pada pukul 6.00. dari ketiga parameter tersebut dapat ditarik kesimpulan bahwa ada dua kategori kondisi lingkungan ekstrim dalam 24 jam, yaitu saat cuaca paling terang dimana intensitas cahaya tinggi, suhu tinggi serta kelembaban rendah, dan saat cuaca paling gelap dimana intensitas cahaya rendah, suhu rendah serta kelembaban tinggi. Hal ini tentu dapat berpengaruh pada arus bocor isolator keramik yang sangat tergantung pada kondisi lingkungan. 
Tabel 1. Parameter lingkungan

\begin{tabular}{cccccc}
\hline No & Waktu & $\begin{array}{c}\text { Suhu } \\
\left({ }^{\mathbf{0}} \mathbf{C}\right)\end{array}$ & $\begin{array}{c}\text { Cahaya } \\
(\mathbf{l u x})\end{array}$ & Kelembaban $(\boldsymbol{\%})$ & Ket \\
\hline 1 & $3: 00$ & 22.9 & 0.82 & 87.60 & Berkabut \\
2 & $6: 00$ & 22.2 & 1181 & 90.80 & Berkabut \\
3 & $9: 00$ & 28.8 & 69700 & 51.20 & Cerah \\
4 & $12: 00$ & 31.4 & 88100 & 37.90 & Cerah \\
5 & $15: 00$ & 29.3 & 41500 & 48.60 & Cerah \\
6 & $18: 00$ & 28.1 & 3.21 & 57.40 & Cerah \\
7 & $21: 00$ & 23.6 & 0.66 & 77.30 & Cerah \\
8 & $0: 00$ & 23.3 & 1.52 & 81.40 & Cerah \\
\hline
\end{tabular}

Tabel 2. Hasil pengujian arus bocor

\begin{tabular}{ccc}
\hline No & Waktu & Arus Bocor (Mikro Ampere) \\
\hline 1 & $3: 00$ & 37.9 \\
2 & $6: 00$ & 38.5 \\
3 & $9: 00$ & 27.1 \\
4 & $12: 00$ & 26.3 \\
5 & $15: 00$ & 26.9 \\
6 & $18: 00$ & 31.3 \\
7 & $21: 00$ & 32.3 \\
8 & $0: 00$ & 35.3 \\
\hline
\end{tabular}

Berdasarkan Tabel 2 terlihat bahwa arus bocor tertinggi terjadi pada pukul 6.00 dimana kelembaban tertinggi dan suhu terendah terjadi sehingga dapat disimpulkan ketika udara lingkungan basah mengenai permukaan isolator dapat memicu naiknya arus bocor isolator keramik dimana jenis isolator ini memiliki permukaan yang hidrofilik sehingga mudah menyerap air. Sebaliknya, arus bocor terendah terjadi pada pukul 12.00 dimana kelembaban terendah dan suhu tertinggi terjadi. Pada waktu tersebut permukaan isolator kering sehingga tidak cukup konduktif untuk terjadinya arus bocor. Grafik waktu pengukuran terhadap besar arus bocor ditunjukkan pada gambar 4 .

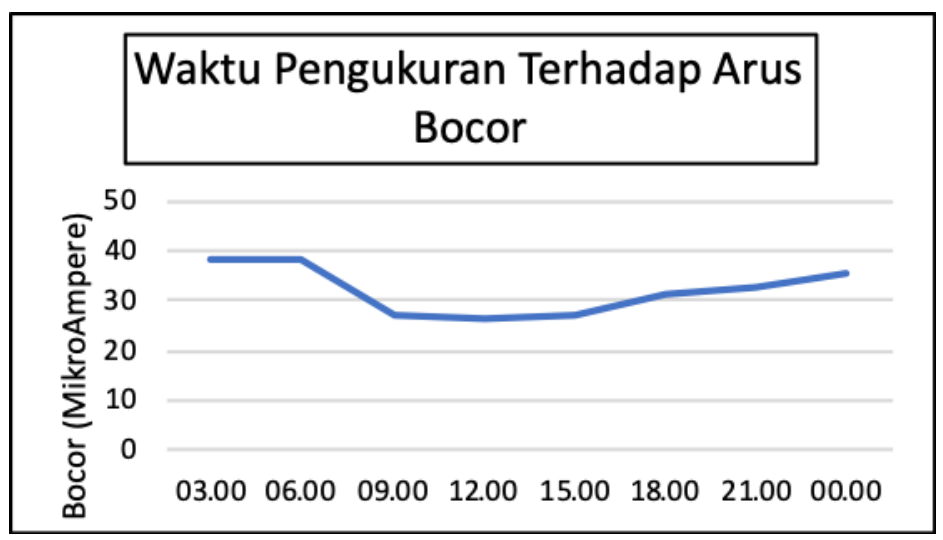

Gambar 4. Grafik waktu pengukuran terhadap arus bocor

Kenaikan arus bocor akibat tingginya kelembaban dapat juga dipengaruhi lokasi penempatan isolator pasang luar. Semakin tinggi konduktifitas udara di sekitar isolator misalnya daerah pantai, maka arus bocor semakin tinggi sehingga dapat memicu terjadinya flashover yang 
mengakibatkan terganggunya system penyaluran tenaga listrik. [10]. Kelembaban tinggi yang terjadi juga dapat meningkat ketika terjadi hujan. Saat itu arus bocor isolator dapat meningkat tajam. Namun keuntungan yang dapat diambil setelah hujan yaitu adanya pembersihan permukaan alami sehingga arus bocor setelah hujan dapat bernilai lebih kecil dibandingkan sebelum hujan [11].

Berdasarkan hasil pengukuran arus bocor isolator keramik dengan parameter lingkungannya, dapat disimpulkan bahwa isolator keramik lebih cocok ditempatkan pada daerah yang cenderung memiliki suhu tinggi sehingga kelembaban lingkungannya cukup rendah. (valdi)

\section{SIMPULAN}

Pengujian Arus bocor isolator dapat menjadi parameter untuk menentukan kondisi isolator. Karena isolator keramik memiliki sifat hidrofilik, maka kelembaban sangat berpengaruh pada besarnya arus bocor dimana semakin tinggi kelembaban, semakin besar arus bocor isolator dimana pada hasil pengukuran selama 24 jam kelembaban tinggi terjadi pada waktu malam hari.

\section{DAFTAR PUSTAKA}

[1] Isaias, R., Ramiro, H., dan Gerardo, M. (2012). "Measurement of Leakage Current for Monitoring the Performance of Outdoor Insulators in Polluted Environments", IEEE Electrical Insulation Magazine, 28, No. 4.

[2] Meyer, L.H., dkk. (2011). "A Study of the Correlation of Leakage Current, Humidity and Temperature of $25 \mathrm{kV}$ Insulators in Urban and Rural Areas", Annual Report Conference on Electrical Insulation and Dielectric Phenomena.

[3] Dini, F., Heldi, A., Rachmawati, dan Suwarno. (2017). "The Effect of Coating on Leakage Current Characteristic of Coast Field Aged Ceramic Insulator", 4th International Conference on Electrical Engineering, Computer Science and Informatics (EECSI).

[4] Waluyo, Ngapuli, I. S., Suwarno, dan Maman A.D., (2010). "Leakage Current and Pollutant properties of Porcelain Insulators from the Geothermal Area", ECTI Transactions on Electrical Eng., Electronics, And Communications 8, No.1.

[5] Lanto, M. K. A. (2012). "Analisis Pengujian Arus Bocor Line Post Insulator 70 KV yang Terkontaminasi Polutan Industri”, Jurnal Ilmiah Foristek 2, No. 1.

[6] Muhammad, A., Salman, dan Ali. (2009). "Monitoring of Leakage Current for Composite

Insulators and Electrical Devices", Advanced Study Center Co. Ltd.

[7] Pylarinos, dkk. (2010). "Monitoring Leakage Current Waveforms in the Field", 7th Mediterranean Conference and Exhibition on Power Generation, Transmission, Distribution and Energy Conversion (MedPower 2010).

[8] Dianisios, P., Kiriakos, S., Eleftheria, P. (2011). "Measuring and Analyzing Leakage Current for Outdoor Insulators and Specimens", Advanced Study Center Co. Ltd.

[9] Obet. P., dan Syahrawardi. (2016). "Pengaruh Kelembaban Terhadap Arus Bocor Isolator Piring Jenis Porselen Terpolusi Abu Vulkanik". Jurnal Singuda Ensikom 14, NO.38. 
[10] Kailin, W., dkk. (2015). "Analysis on Flashover Performance of Polluted Porcelain Insulators in High Conductivity Fog Environment", Annual Report Conference on Electrical Insulation and Dielectric Phenomena.

[11] Zico, V., dan Hendra, Z. (2014). "Pengaruh Pembersihan oleh Hujan Terhadap Arus Bocor Isolator Pin-Post 20 Kv Terpolusi”, SINGUDA ENSIKOM 8, No. 2. 